\section{Politicidade do Cuidado e Avaliação em saúde: instrumentalizando o resgate da autonomia de sujeitos no âmbito de programas e políticas de saúde}

\author{
The political content of evaluation and \\ healthcare: providing the tools to rescue the \\ autonomy of subjects in the scope of \\ programs and healthcare policies
}

Maria Raquel Gomes Maia Pires 1

\author{
${ }^{1}$ Núcleo de Estudos em Educação. Promoção da Saúde e Projetos \\ Inclusivos. Centro de Estudos Avançados Multidisciplinares. \\ Faculdade Ciências da Saúde. Universidade de Brasília. Ca, j 7. \\ Sala 34. Campus Universitário Darcy Ribeiro. Brasília, DF, Brasil. \\ CEP: 70.910-900. E-mail: raquelpires@ unb.br
}

\begin{abstract}
The political content of care relates to the disruptive management of the relationship between care and power to build subjects autonomy, expressed by three conceps "knowledge for improved care, care to confront, care to emancipate". This discussion concerns the controversial or political content of health evaluation, focusing on the power relationships permeating the assessment process. It deals with a theoretical and phylosofical issue with the purpose of: (a to design a theoretical concept of the political nature of care and the threefold emancipation basis of care; b) to discuss the emancipation concepts of assessment from the political nature of care and c) to introduce a methodological reference supporting the assessment of healthcare programs based on the political nature of care, centered on subject autonomy. The intention is to indicate the possible application of the concept of the political nature of care in the scope of healthcare policies, programs and services, signaling towards the emancipation potential required to the implementation of the Universal Healthcare System (SUS - Sistema Universal de Saude). That is, assessment needs to become more democratic and viewed as a tool of citizenship change and empowerment.
\end{abstract}

Key words Evaluation, Health policy, Peer review, health care

\section{Resumo}

Politicidade do cuidado diz respeito ao manejo disruptivo da relação entre ajuda e poder para construção da autonomia de sujeitos, expressa pelo triedro "conhecer para cuidar melhor, cuidar para confrontar, cuidar para emancipar". Essa discussão reflete-se sobre as ambivalências ou politicidades da avaliação em saúde, centrando-se nas relações de poder que permeiam o processo avaliativo. Trata-se de uma reflexão teórico-filosófica que objetiva: a) conceituar teoricamente politicidade do cuidado e triedro emancipatório do cuidar; b) discutir as concepções emancipatórias de avaliação a partir da politicidade do cuidado e c) apresentar um referencial metodológico que subsidie a avaliação de programas de saúde a partir da politicidade do cuidado, centrando-se na autonomia de sujeitos. Pretende-se indicar aplicabilidades à concepção da politicidade do cuidado no âmbito da avaliação de políticas, programas e serviços de saúde, sinalizando potencialidades emancipatórias necessárias à implementação do Sistema Único de Saúde (SUS). Ou seja, há que se democratizar a avaliação, tornando-a cada vez mais instrumento de mudança para fortalecimento de cidadanias.

Palavras-chave Avaliação, Política de Saúde, Cuidados de saúde avaliados pelos pares 


\section{Introdução}

A partir de concepção ampla de cuidado, que nas dimensões ecológica, social e política pode ser entendido como mediação dinâmica entre ajuda e poder, argumenta-se em favor do potencial disruptivo e inovador inerente ao gesto de cuidar, tanto capaz de tutelar quanto de emancipar pessoas. Falase em politicidade do cuidado para caracterizar o movimento de integração, confronto e ruptura presente nas dinâmicas vivas que se estabelecem entre os seres em geral e, em particular, entre os humanos. Ou seja, significa entender o cuidar no âmbito da centralidade do político que lhe define, onde a mesma proteção zelosa que lhe delineia pode se constituir tanto em mecanismo de dominação, quanto em instrumento da autonomia dos sujeitos, sejam esses profissionais, técnicos, gestores ou usuários.

No embalo de tais reflexões, fruto de tese de doutorado que analisou a aplicabilidade da politicidade do cuidado à gestão de políticas de saúde, 1 fazse uma discussão sobre as concepções emancipatórias da avaliação em saúde, centrando-se principalmente na intrínseca relação de poder que envolve o processo avaliativo. Aprofunda-se a idéia central de que a politicidade do cuidado - manejo da ajudapoder capaz de subverter assimetrias, expresso pelo triedro "conhecer para cuidar melhor, cuidar para confrontar, cuidar para emancipar" - constitui-se uma referência teórico-metodológica para avaliar programas e políticas de saúde, contribuindo para o fortalecimento da autonomia de sujeitos. $\mathrm{Na}$ primeira parte do texto fala-se teoricamente sobre a politicidade do cuidado e seu triedro emancipatório. Em seguida, e a par dessa discussão, discutem-se as ambivalências e ambigüidades da avaliação em saúde, destacando-lhe o caráter classificatório, autoritário e, ao mesmo tempo, instrumentalizador de mudanças e utopias. Por fim, numa síntese sempre provisória, propõe-se um referencial metodológico que possa subsidiar a avaliação de políticas e programas de saúde a partir da politicidade do cuidado, centrando-se no protagonismo de sujeitos. Pretende-se, sobretudo, apresentar instrumental capaz de indicar cenários de autonomia e poder no contexto das políticas e programas de saúde, sobre os quais se pode avaliar para conhecer e cuidar melhor, numa propulsão capaz de reordenar poderes instituídos e fomentar cidadanias.

\section{Politicidade do cuidado: conhecer para cuidar melhor, cuidar para confrontar, cuidar para emancipar}

A politicidade do cuidado pode ser entendida como manejo político e reconstrutivo da relação dialética estabelecida entre ajuda e poder para a construção de autonomias de sujeitos, sejam esses gestores, técnicos, profissionais de saúde, usuários dos serviços de saúde, família, comunidade, enfim, cidadãos. Sobre politicidade, Demo $^{2}$ concebe-a como intrínseca disrupção por mudanças e inovação dos seres vivos, numa busca imanente por autonomia crescente. Assim, o enfrentamento dos limites postos, sejam sociais, econômicos, culturais ou biológicos, conforma o centro nevrálgico e motor da politicidade. Distanciando-se de qualquer fechamento determinista, é possível observar nesse diálogo aspectos que sugerem uma inter-relação dos fenômenos naturais, sociais e históricos presentes na realidade. Tais construções podem ser sintetizadas nos seguintes pontos: a) politicidade, antes de ser razão humana, lateja na matéria, estando presente como dinâmica de reconstrução tanto nos processos vivos, como nas movimentações moleculares, atômicas e sub-atômicas que conformam os elementos da natureza; b) os animais são seres políticos porque também se relacionam, interagem, tensionam e transformam entre si, como se observa, por exemplo, nas formas de associação entre seres vivos estudadas pela biologia (cooperação, mutualismo, competição, simbiose, sociedade, entre outros); c) essa politicidade, no homem, se complexifica, assumindo peculiaridades próprias do ser dialético que sabe intervir pela reconstrução permanente; d) tal "intervenção" humana, no capitalismo, tem intensificado a face agressiva e desigual das relações sociais, sendo necessário o resgate da dimensão ética dessa mesma politicidade, capaz de forjar processos emancipatórios.

Ainda sob as descobertas das ciências naturais, $o$ pulsar dos fenômenos vivos, tão irreverentemente caracterizados tanto pela "termodinâmica dos processos irreversíveis"3 (movimento de turbulência e revolução presente no aquecimento das moléculas químicas que gera dissipações irrepetíveis, singulares e transformadoras na estrutura das mesmas), em Prigogine, quanto pela "autopoiese"4 (autonomia ou auto-eco-organização dos processos do organismo vivo), em Maturana e Varela, consubstanciam um forte argumento em favor da politicidade. O caráter disruptivo, "autopoiético e irreversível" inerente aos seres vivos, concebido de maneira dialógica e dialética, fundamenta o argumento da politici- 
dade do cuidado. Nessa direção, entende-se cuidado como reconstrução da ajuda para fortalecimento da autonomia do outro (reconstruída na relação intersubjetiva do encontro), calcada em relações de poderes potencialmente subversivas que podem tanto oprimir, quanto (re)inaugurar possibilidades emancipatórias. A autonomia intrínseca dos sujeitos como potencial transformador, a historicidade e dinamicidade de uma realidade complexa e imprevisível, configuram a idéia da "politicidade do cuidado enquanto gestão inteligente da ajuda-poder". É precisamente pela politicidade que o cuidado pode se tornar emancipatório ou desconstrutor das próprias estruturas que o subjugam. Trata-se de redimensionar o cuidado como possibilidade ética da humanidade, viabilizável pela ambivalência intrínseca. Tal intento sugere um movimento dialético no qual a relação de dependência acontece mais para construir emancipação dos atores envolvidos, que para manter-se em si mesmo, como exercício autocentrado de poder. Ou seja, significa cuidar para que possamos ser capazes de reelaborar cada vez mais a tutela e exigir cidadania, onde o 'meu' projeto de autonomia só existe enquanto parte integrante da autonomia coletiva, sabendo-a sempre relativa.

O cuidado como gestão da ajuda-poder tem como fulcro central a dinamicidade tanto dos processos históricos, quanto da natureza, assumindose aqui uma abordagem social, ecológica e epistemológica do cuidar. 5 É precisamente pelo conflito e incerteza presente no gesto de ajuda que ele pode vir a ser uma força revolucionária, traduzindo-se em politicidade. Compreender o cuidado como vir a ser, contrário de ser, contemporiza-o como possibilidade de mudança inerente às relações sociais. A liberdade manifesta na concepção do vir a ser constitui a potencialidade subversiva do cuidado, expressa pela frivolidade, fugacidade e intrínseca transitoriedade do fenômeno do poder. O cuidado visto na totalidade envolve não só o modo de ser, estrutura mais definidora e capturável, como também o modo de vir a ser, característica que o torna dinâmico, permeado por volúpia e tensão dialética. Por esse prisma, vislumbra-se o cuidado como uma reconstrução inconteste de si mesmo, em sentido relacional, e da própria natureza.

Boff, 6 apoiando-se em Heidegger, 7 reconhece o cuidado como "modo de ser" essencial, como ethos humano e dimensão ontológica impossível de ser totalmente desvirtuada. Defende que o cuidado entra na constituição da natureza e do ser humano, sem o qual não haveria a própria vida. Com o tom profundamente humano, filosófico e teológico, propõe uma resignificação do cuidado, fundado numa nova "ética do humano e na compaixão pela terra". A consistência teórica de Boff, a despeito de certa tendência esotérica tão pouco ambivalente, torna seu "saber cuidar" uma referência importante para as utopias humanas. Outro destaque oportuno é a crença de que o cuidado, em sentido irrestrito, reside na imanência da vida e do humano, admitindo-se aqui uma plenitude incapturável apenas pela razão. Importante destacar que o entendimento existencial do cuidado como "sabedoria prática"que permeia a "dimensão dialógica do encontro" tem sido revisitada com singular consistência a originalidade no âmbito das práticas de saúde, 8 traduzido-se em amplas possibilidades de ação no processo de adoecimento.

Longe de se adentrar nesta "seara" filosófica, por fugir aos objetivos deste texto, cabe considerá-las como referências importantes para o elemento de ruptura presente nas expressões do cuidar - imanente em possibilidades, transcendente em desafios. Seja qual for a tendência pretendida, a capacidade revolucionária do cuidado ocorrerá menos pelo seu modode-ser que pelo seu modo-de-vir-a-ser. É principalmente pelo que ainda não é, já sendo em si, que se pode argumentar em favor da emancipação. Ou, é precisamente pela dinâmica da liberdade, aproximativa de realizações e plena de desejos, que as utopias libertárias se realizam. 9 Acreditar que as ações solidárias e revestidas de autoridade, ou seja, fundadas em relações de poder próprias do sujeito que ajuda ao outro e define-se a si mesmo, podem promover autonomias capazes de vir a reordenar desigualdades, implica em conceber a centralidade do político nas relações sociais estabelecidas. É pela mediação de interesses, pela negociação árdua de projetos, pela intensidade da ágora ${ }^{9}$ público/privado inerente às sociedades humanas que as pretensas liberdades tomam concretude. O cuidado como ajuda que se re-elabora na relação de poder estabelecida acontece principalmente pela politicidade do cuidar, entendida tanto pelo seu modo de ser solidário, como pelo seu modo de vir a ser político.

Tome-se "ajuda" na concepção discutida por Gronemeyer, 10 que apresenta-a como poder elegante. A autora argumenta que a ajuda ao desenvolvimento, em especial aquela oferecida aos países do “Terceiro Mundo", sempre se constituiu num mecanismo de dominação, onde a dissimulação e extrema discrição lhe foram sempre atributos principais. A caracterização da ajuda como obrigação moral, dever ou imposição cultural é inerente às formações dos distintos povos. Para Mauss, 11 o estudo da dádiva aparece em diferentes civilizações em seu sentido 
desinteressado e obrigatório ao mesmo tempo, expressando-se sobretudo pela seguinte trilogia: a obrigação de dar, a obrigação de receber e a obrigação de retribuir.

Como todo poder que se preza em manter-se forte, a ajuda atua por mecanismos camuflatórios, lançando mão de apelos pretensamente morais para consolidar sua hegemonia. Afinal, quem ousa desconfiar daquele que está "ajudando" o outro, seja através de benesses ou do conhecimento científico? Tome-se o caso dos micropoderes presentes no processo de trabalho em saúde: como duvidar do médico, que além de deter o conhecimento sobre o meu corpo e minha doença, promove o bem da minha saúde a partir do seu saber-poder?12 Por oportuno, cabe ponderar que a avaliação tem servido de instrumento legitimador de poderes na sociedade moderna, ajudando a manter hegemonias e maiorias nem sempre justas em diferentes cenários e contextos, sendo associada muito mais a punições e repreensões, que a libertação ou transformação.

O poder, situação estratégica complexa, permeada por disputa e sublevações num determinado contexto sócio-histórico, 12,13 encarrega-se mais da vida (ou da reprodução social) do que da ameaça da morte, dando-lhe acesso direto ao corpo biológico articulado intrinsecamente com a história. Para Foucault, é principalmente por meio desta "biopolítica”, que negocia domínios sobre a vida na história dos homens, que o saber-poder tem se constituído como um "agente de transformação da vida humana". Para o autor, e referindo-se à história da sexualidade humana, o mesmo interdito que mantém o corpo disciplinado aos desígnios do capitalismo, submetido às normas sociais que mantêm os corpos dóceis e hígidos para a reprodução do capital, pode se contrapor a estes comandos por uma mesma biopolítica interna, libertando-se da tutela por meio do cuidado de si, capaz de forjar autonomias. Nessa linha de pensamento, e acompanhando as transformações do capital, que hoje rompe barreiras físicas e territoriais, o poder igualmente se fragmentou nos corpos humanos, perdendo em unidade definidora capturável, ganhando em extensão irrepreensível.14 Significaria dizer que, apesar da coerção externa, hoje as pessoas obedecem ou não muito mais por dinâmica interna, por uma biopolítica que lhe é intrínseca. É precisamente sobre essa dimensão política da vida das pessoas que o poder age, por mecanismos internos de controle mediados pelo biopoder. Ao contrário do que se poderia supor, a política não desaparece, mas sim sua soberba autonomia. Em diálogo com esses autores, argumenta-se aqui por uma "proposição disruptiva do cuidar" por um cuidado que se reconstrua sempre para cuidar melhor, gerindo politicamente relações da ajuda-poder.

\section{Triedro emancipatório do cuidar: conhecer para cuidar melhor, cuidar para confrontar, cuidar para emancipar}

A politicidade do cuidado está calcada na reconstrução da autonomia de sujeitos por meio da gestão da ajuda-poder. A defesa dessa concepção se fundamenta pelo que aqui se denomina "triedro emancipatório do cuidar: conhecer para cuidar melhor, cuidar para confrontar, cuidar para emancipar" (a escolha da metáfora do triedro, meramente ilustrativa, foi inspirada no fato dessa figura geométrica ser formada constitucionalmente por três faces integradas, visualizadas em conjunto e gerando diversas imagens a depender da posição e incidência do jogo de luz e sombras possíveis). Com tal proposição, argumenta-se em favor do conhecimento como forma natural de participar de um mundo socialmente fundado em relações de ajuda-poder. Articulando saber e poder, ou reconhecendo que o cuidado é também uma forma de conhecimentoavaliação (de si mesmo, do outro e do aprendizado que se reconstroi dessa intersubjetividade) capaz de forjar possibilidades libertárias, pode-se ampliar a capacidade de confronto e reordenamento das assimetrias de poder, emancipando por meio da mesma ajuda que domina e subjuga. Desconstruir progressivamente relações de domínios por meio de ações solidárias implica um resgate crítico da discussão sobre conhecimento e poder, que sempre foi tensa e dialética. Sobre tal questão, Morin 15 defende a idéia de que o conhecimento tem uma "vocação emancipatória", a qual quanto mais se conhece e se compreende, mais se é capaz de, reconhecendo os limites do "verdadeiro", dedicar-se à sua procura e, por meio desse processo incessante de busca, emancipar-se relativamente de certas concepções. Diante do desafio da complexidade do real, urge ao conhecimento refletir-se sobre si mesmo, situando-se e problematizando-se no exercício processual de aproximar-se da realidade.

Caso tal conhecimento possa ser visualizado como uma forma de participar da vida - e se o homem é estruturalmente cuidado como modo de ser-no-mundo junto aos entes intramundanos 6,7 - o ato de cuidar também pode ser concebido enquanto forma de conhecer, avaliar e reinventar cotidianos. Para se cuidar uns dos outros, numa propulsão tanto criativa quanto dominadora, incorpora-se, apreendese e interpreta-se a realidade. Nesse espírito amplia- 
do, entenda-se conhecimento como dinâmica viva de produzir interpretações, significados, críticas e formas de participar da realidade. Conhecer é reconstruir possibilidades de conviver, atuar e interagir com o planeta, concebendo a disrupção, o confronto e a provisoriedade como cerne. É a maneira como a natureza se mantém diversa, única e incapturável, reconduzindo tempos, espaços e histórias de forma não-linear e irredutível. Precisa-se, então, "conhecer para cuidar melhor, cuidar para confrontar, cuidar para emancipar", porque tal politicidade se expressa na intrínseca habilidade de cognição presente na natureza, na cultura e na história da humanidade.

Os seres humanos são permeados por cuidado e destruição, ajuda e coerção, exprimindo-se pela tensa disputa entre loucura e sapiência que os encerra. $\mathrm{O}$ ato de cuidar sofre pressões tanto da racionalidade empírica-prático-instrumental, como das pulsões incontroláveis e delinqüentes que integram o homo sapiens-demens (onde o humano se caracteriza não apenas pelo lado racional, mas igualmente pela demência e pulsão destrutiva que lhe completa). 16 Misto de estratégia, ruptura e submissão, o cuidado transita entre a humanidade sapiens e demens, unindo-as numa propulsão reorganizadora de poderes conformados. A politicidade do cuidado contempla o potencial da mudança, da desconstrução reconstrutiva, da ruptura dos interditos e sublevações opressivas, tendo por foco a construção da autonomia, síntese de diversos modos de cuidar. Trata-se de uma "autonomia dependente, "16 porque não existe autonomia viva que não seja dependente (do meio, da auto-organização, da energia vital, da cultura, da história, da família, da sociedade, do Estado) ou "polidependente". A liberdade do sujeito autônomo ocorreria numa situação que comporte, ao mesmo tempo, ordem e desordem, estabilidade e regularidade, certezas a priori para que seja possível escolher e decidir num mínimo de desordem e risco. A autonomia do humano se funda na qualidade de sujeito que se auto-afirma ocupando o centro do seu mundo, mas que comporta um nós (família, espécie, sociedade), uma inscrição comunitária (família, pátria), hereditária, histórica e cultural.

O triedro emancipatório do cuidar propõe-se a desenvolver uma epistemologia dialética do cuidado que ganhe em intensidade subversiva, mesmo sendo relação de dominação. O cuidado aqui proposto contempla toda a ambigüidade e complexidade do sujeito discutida por Morin16 fundamentando-se eticamente na emancipação dos sujeitos. A gestão da ajuda-poder para a emancipação de sujeitos envolve "conhecer para cuidar melhor, cuidar para confrontar, cuidar para emancipar", pois precisa-se entender mais profunda e dialeticamente a realidade complexa para nela agir e cuidar, em nome de uma ética mais justa, cuidadora, igualitária e libertadora. Tal intervenção cuidadora e subversiva pode fortalecer autonomias e qualificar enfrentamentos, emancipando pela desconstrução progressiva de assimetrias de poder.

\section{Politicidades da avaliação em saúde: avaliar para tutelar ou para cuidar da autonomia de sujeitos?}

Compreender a avaliação como perspectiva de mudança pressupõe antever-lhe ambivalências e tensões, próprias das relações de poderes que lhe conformam. Significa também concebê-la dentro da limitação e parcialidade que lhe encerra, uma vez que avaliar, como instrumento privilegiado do conhecimento, exige delineamento de cotidianos, sendo sempre provisória e incompleta, por se fazer. As politicidades da avaliação de políticas, programas e serviços de saúde tornam as ambigüidades mais prementes, uma vez que se vem procurando fortalecê-la enquanto instrumento de gestão e implementação do Sistema Único de Saúde, de concepção universalista e solidária, num contexto marcado pela hegemonia do mercado e competitividade sobre a cidadania das pessoas. 1

Para o que aqui se vem discorrendo, veja-se a avaliação em saúde como racionalidade críticoinstrumental de determinados recortes de políticas, programas, projetos, serviços e práticas que objetivam parametrizar, classificar ou escalonar informações sobre o cenário estudado, com a finalidade de indicar ações e/ou (re)programações a serem implementadas. Nesse sentido, e aqui reside a politicidade que se pretende destacar, tanto pode oprimir e tutelar sujeitos, quanto subsidiá-los no processo de tornarem-se protagonistas da realidade avaliada, potencializando reconstruções possíveis. No âmbito da politicidade do cuidado, pode ser entendida como ajuda técnica que viabiliza a identificação de situações-problemas e enfrentamento das mesmas por meio de ações, recursos, atores e estratégias, sendo permeada por relações de poderes. Nesse sentido, tanto é capaz de manter opressões, quanto de fomentar sublevações, dependendo do uso que dela se faz, pois não existe neutralidade no processo de discriminar e comparar situações-problemas. $\mathrm{Na}$ tensa disputa entre ajuda e poder, a avaliação pode tanto camuflar situações subjacentes ao fenômeno 
estudado e que a sustentam, quanto evidenciar-lhe em todas as nuances e contradições, podendo provocar rupturas de ordens solidamente instituídas.

Apesar das concepções mais críticas sobre avaliação dos últimos anos, 17 que vêm cada vez mais considerando os sujeitos e a dinâmica da realidade como fatores inerentes ao cenário foco da verificação, cabe ponderar que o caráter estruturalfuncionalista, positivista e autoritário ainda é hegemônico nesse campo do conhecimento, embora em intensa disputa com outras vertentes de cunho mais dialéticas. Nesse sentido, não é preciso muito esforço para se identificar os desconfortos gerados pela iminência do ato avaliativo. $O$ medo do fracasso, da nota baixa, do indicador baixo, da repreensão e da inevitável exclusão advindas dos processos avaliativos conformam a maioria das expectativas negativas que as pessoas têm em relação a esse mecanismo de domínio. O poder de avaliar e outorgar diagnósticos, em qualquer área de conhecimento e em especial na saúde, costuma ser extremamente verticalizado, linear, mecanizado, limitador de diversidades e possibilidades libertárias. Prescrever e proscrever condutas sobre corpos e almas enfermas são práticas recorrentes e comuns dos profissionais de saúde, que as fazem com o auxílio de todo um arsenal tecnológico e terapêutico que subsidia a anamnese, por exemplo. Em âmbito coletivo, igualmente se tem planificado realidades de pessoas em indicadores e taxas de doenças, pouco se priorizando a singularidade e potencialidade dos sujeitos na (re)construção de cidadanias e utopias libertárias. Muito raramente se tem democratizado o poder de avaliar diagnosticar e tratar as doenças por meio do partilhar de experiências com usuário e população, a despeito de toda a discussão sobre mudança do modelo assistencial em saúde. 18 No mais das vezes se tem classificado de forma prescritiva a saúde de "pacientes", "comunidades" ou municípios, seja em sentido individual ou coletivo, reeditando opressões e assimetrias, seja entre níveis de governo (por meio de políticas de avaliação verticalizadas de sistemas, programas ou serviços de saúde), seja entre profissionais e usuários (por meio de abordagens medicalizantes e pouco dialógicas). Em outras palavras, se tem avaliado muito mais para tutelar e controlar realidades que para transformálas, posto que para tal se precisa ampliar oportunidades e autonomias, democratizando relações de poderes e vulnerabilizando autoridades.

Se bem reparado, os processos avaliativos que integram as práticas de saúde estão calcados na racionalidade do paradigma moderno, caracterizado pela extrema decomposição e fragmentação do todo em partes, pela intervenção destrutiva, pela linearidade de procedimentos, técnicas e métodos, e pela crença inequívoca de que a realidade pode ser plenamente conhecida, classificada, esmiuçada. Em época de transição paradigmática, 19 complexidade ${ }^{15,16} \mathrm{e}$ realidade ambígua, ambivalente e não-linear, 20 tal modernidade tem ficado cada vez menos sustentável, uma vez que a própria ciência vem se flagrando impotente para dar conta do real, como atestam as recentes descobertas da biologia, ${ }^{4}$ química ${ }^{3}$ e física quântica. ${ }^{21} \mathrm{O}$ tempo das horas marcadas, dos movimentos repetidos e previsíveis, das estruturas rígidamente imutáveis e da linearidade dos fenômenos vem se fluidificando em espaços-tempos plurais, pondo em cheque as pretensas verdades da modernidade. 9

Amparada em racionalidade cartesiana pouco ambivalente, a avaliação calcada no positivismo contrasta quantidades e qualidades, qualifica desempenhos, acompanha metas e resultados, compara situações, estabelece padrões, classifica. Como propriedade logicamente fundada, utiliza muito mais a programação cerebral, que a interpretação dúbia dos fatos, a cogitação e intuição. Ou seja, compara, lineariza, simplifica, reduz cenários, quantifica, isola, fragmenta, formaliza, disseca, prova, aprova, reprova, manipula, ensaca, encaixa e estabelece médias, donde advém mediocridades. Tal tipo de avaliação é limitada porque fundada em causalidades recorrentes, em crenças de universalidades discriminatórias, em padrões e parâmetros que desconsideram a dinâmica e processualidade histórica. Em outros termos, anular a politicidade da avaliação, traduzida pela tensa disputa que se estabelece entre a regra e o movimento de atores inseridos em contextos complexos, fragiliza e engessa movimentos libertários, restringindo utopias e possibilidades de reconfiguração de poderes conformados.

Ao invés de normas calcificadas na presunção de que é possível separar as estruturas dos processos e resultados que lhe fundam, ${ }^{23}$ como se fosse possível discriminar o tempo do espaço, o ser do tempo, a matéria do espírito, a estrutura da história, urge a necessidade de refundar os modos de aplicar a avaliação na totalidade dos processos dinâmicos, parciais e provisórios que conformam as realidades sóciohistóricas. Na área de saúde em especial, solidamente calcada no paradigma biomédico positivista, há que se apostar muito mais na intrínseca politicidade dos métodos avaliativos, capaz de despertar críticas, desconstruções e reconstruções pelos sujeitos envolvidos, que na cristalização de dogmas pouco ambivalentes, inibidor de subversões e inovações. 
O potencial transformador e indicador de caminhos libertários da avaliação residiriam justamente na provisoriedade dos diagnósticos, na eterna insegurança que alimenta buscas incessantes, na percepção de que quaisquer métodos ou técnicas escolhidos são sempre limitados para dar conta dos complexos cenários a que se propõe retratar. Tal percepção põe em crise a maioria dos instrumentos avaliativos e, em especial, os epidemiológicos, sempre tão preocupados com validades e confiabilidades de indicadores. Compreender a politicidade da avaliação como possibilidade de mudança significa entender as limitações dos processos verificativos, não para rejeitá-los, mas para aperfeiçoar interpretações sobre a realidade e sobre os métodos empregados para mensurá-la, validá-la, contrastá-la, dissecá-la, sabendo-os, porém necessários, parte, jamais o todo.

Apostar na politicidade da avaliação como estratégia emancipatória pressupõe concebê-la num cenário de ambigüidade, vulnerabilidade e transitoriedade, entendendo-a como fenômeno de poder intrínseco. Significa entender o poder outorgatório da avaliação dentro da fragilidade e circurstancialidade de realidades complexas, percebendo sua potencialidade subversiva e desconstrutora. A politicidade da avaliação não nega o fenômeno do poder, adota-o como trunfo para virar a mesa do jogo e resgatar o sujeito (seja usuário dos serviços de saúde, profissionais de saúde, técnicos das secretarias de saúde) como protagonista privilegiado da ação classificatória, instrumentalizando a indicação de estratégias de superação dos problemas identificados. Investir ou focalizar os fenômenos de poder inerentes aos processos avaliativos significa transcender a tutela e outorga dos tradicionais instrumentos adotados, priorizando a criatividade e elaboração própria.

Para tanto, há que se democratizar a avaliação,dando oportunidade para que os poderes se expressem também de baixo para cima, a partir das necessidades dos avaliados. Nesse espírito ampliado, há que se avaliar também o avaliador, tornando-o partícipe da situação que se pretende modificar. Outros recursos importantes para partilhar os poderes do ato avaliativo podem ser brevemente sintetizados no seguinte: a) na adoção de critérios transparentes, sempre reconstruíveis; b) possibilidade de refazer; c) os avaliados precisam entender porque e como estão sendo avaliados; d) avaliação como meio de aperfeiçoar aprendizagem, não como mecanismo de repressão; e) avaliar para promover sujeitos, não para objetá-los; f) permitir críticas e discutibilidade dos resultados como forma de re- construí-los e transformá-los; g) nota, padrão ou meta averiguada sempre sujeita a revisão, jamais definitiva; h) permitir novas chances de avaliação, utilizando-a como busca de qualidade que nunca se finda.

Entender a avaliação como um processo de análise, crítica e indicações para uma dada realidade pressupõe antever-lhe a vertente emancipatória, capaz de transformá-la em sentido qualitativo, praxiológico, libertador e político-pedagógico. ${ }^{23}$ Nesse sentido, a politicidade aparece como centralidade maior a ser priorizada, porque vulnerabiliza poderes instituídos, podendo fortalecer cidadanias. Afinal, mudar um determinado contexto é fenômeno político, tenso e conflituoso, envolvendo negociação entre as relações de ajuda e poder das pessoas envolvidas no processo.

Desconstruir regras, procedimentos tácitos e relações estabelecidas no âmbito de programas, políticas, instituições, práticas e serviços em saúde faz parte das discussões atuais sobre mudança do modelo assistencial. Avaliar para mudar exige, sobretudo centralidade nos sujeitos, regatando-lhes a autonomia e o fortalecimento de aprendizados múltiplos, subsidiando o empowerment coletivo. 24 Numa tentativa de articular o triedro emancipatório do cuidar ao processo avaliativo, pode-se vislumbrar a seguinte máxima: "avaliar para conhecer e cuidar melhor, avaliar para indicar cenários de autonomia e poder, avaliar para cuidar da autonomia de sujeitos". Ou seja, precisa-se da avaliação como meio para reconstruir formas de apreender, interpretar e participar de cotidianos, aperfeiçoando o cuidado como mediação inteligente da ajuda e poder (avaliar para conhecer e cuidar melhor). A partir da ampliação de cenários e perspectivas propiciados (em parte) pelos processos avaliativos, há que se indicar possibilidade de fomento e resgate da autonomia de sujeitos (avaliar para indicar cenários de autonomia e poder), instrumentalizando a democratização de saberes, relações de ajuda-poder e cidadanias (avaliar para cuidar da autonomia de sujeitos).

\section{A avaliação em saúde a partir do triedro emancipatório do cuidar: identificando cenários de autonomias, potencializando cidadanias}

Investir na avaliação como instrumento que subsidie a indicação de cenários propícios à autonomia de sujeitos parece ser a principal aplicabilidade do diálogo que se vem objetando entre a politicidade do cuidado e as concepções críticas dos processos 
avaliativos. Tal prerrogativa tem sido pouco priorizada em muitos dos instrumentos e técnicas utilizadas para avaliar programas e serviços de saúde, seja porque a premência da doença imprime uma certa focalização na epidemiologia clássica, seja porque a gestão dos sistemas e serviços de saúde igualmente exige respostas ágeis em relação ao acesso e resolubilidade dos mesmos. A despeito das premissas programáticas serem plenamente justificáveis, há de se considerar que a profundidade dos princípios doutrinários do SUS, em especial a eqüidade e participação social, pressupõem o fomento à centralidade nos sujeitos como protagonistas na luta e conquista do direito à saúde.

Por ser oportuno, e na tentativa de conferir certa aplicabilidade instrumental ao que se vem discutindo, esse tópico apresenta algumas referências teórico-metodológicas que subsidiam a construção de indicadores avaliativos no âmbito de políticas, programas e serviços de saúde a partir do triedro emancipatório do cuidar. Ressalte-se o caráter iminentemente qualitativo da proposta, uma vez que o objeto que se pretende priorizar é a identificação de cenários propícios à autonomia de sujeitos nos diversos espaços e ações onde a política de saúde se operacionaliza. Para tanto, far-se-á uma conversa entre o triedro emancipatório do cuidar e o referencial analítico da hermenêutica de profundidade. $25 \mathrm{O}$ triedro do cuidar aqui defendido articula sinteticamente as categorias cuidado, poder e emancipação numa perspectiva epistemológica, ética e política. Aposta-se num conhecimento que torne possível relações de ajuda-poder mais igualitárias. Há de se promover um cuidar que faça emergir as tensões e contradições da arena política, numa perspectiva fortalecedora de sujeitos históricos.

Para visualizar como a autonomia de sujeitos vem sendo produzida no campo da política de saúde do Brasil, há que se investir num instrumental analítico que considere o contexto, as relações sociais e as dinâmicas que ocorrem na realidade estudada. A hermenêutica de profundidade (HP) 25 parece adequar-se a essa necessidade, uma vez que procura analisar como os discursos vêm sendo produzidos para manter relações de poder. Calcado na teoria crítica e teorizando sobre ideologia, cultura e comunicação de massas na sociedade moderna, Thompson propõe um arcabouço metodológico para instrumentalizar análises de discursos. Em linhas gerais, esse referencial propõe interpretar como as "formas simbólicas" (construções significativas que exigem interpretação) são empregadas para manter relações de poder, ao que denomina "ideologia". O autor sistematiza o referencial em três âmbitos: análise sócio-histórica, análise formal ou discursiva e interpretação/reinterpretação. A análise sóciohistórica diz respeito às condições conjunturais em que as formas simbólicas são produzidas e conformadas. A análise formal ou discursiva procura desvelar a estrutura da complexidade dos objetos e expressões que circulam o campo social. A interpretação ou reinterpretação procede na realização de sínteses possíveis a partir das etapas anteriores, procurando manter o caráter aberto ou a intenção de tentar se colocar no local do outro.

O estudo das formas simbólicas, ou o desvelamento de discursos a serviço do poder (ideologia), pode ser utilizado não apenas para destrinchar depoimentos, mas igualmente outras formas de comunicação e linguagem. Demo (2001: 45), 26 na releitura que realiza da proposta de Thompson, reafirma:

"(...) pretendemos aplicar tais idéias metodológicas não só a dinâmicas, mas também a desempenhos qualitativos, como é avaliar a qualidade política de uma associação comunitária em sua atuação concreta histórica, por exemplo. A ideologia é tendencialmente entendida como discurso e, por vezes, a proposta de Thompson parece restringir-se às análises qualitativas de discursos. Acrescentamos aqui também a possibilidade de analisar práxis históricas (Vasquez, 1977), sempre que for o caso claro de fenômenos qualitativos intensos." .

A par desse diálogo, cabe dizer que o triedro emancipatório do cuidar, calcado no conhecimento capaz de potencializar confrontos e reordenamentos de poderes, pode orientar a avaliação de políticas de saúde, centrando-se na interpretação de ideologias inseridas em contextos complexos. Inspirados no referencial metodológico de Thompson - e a partir das faces "conhecer para cuidar melhor, cuidar para confrontar, cuidar para emancipar" - é possível delimitar dimensões e parâmetros que podem subsidiar a avaliação em saúde. Tais dimensões decorrem das seguintes interfaces entre o triedro emancipatório do cuidar e a HP: a) articulação do contexto sócio-histórico em que as práticas são produzidas com o "conhecer para cuidar melhor"; b) as correlações de forças existentes no contexto e as disputas entre as produções sociais realizadas se imbricam com o "cuidar para confrontar"; c) a interpretação e reinterpretação das formas simbólicas operam movimentos dinâmicos, potencializando o "cuidar para emancipar". Uma possibilidade de desenho a ser adotado a partir dessa conversa poderia prever três dimensões: a) contexto da política; b) relações institucionais; e c) dinâmica 
Dimensões de análise para políticas de saúde a partir da hermenêutica de profundidade e triedro emancipatório do cuidar

Hermenêutica de profundidade

Triedro emancipatório do cuidar

Dimensão de análise

Hermenêutica da Vida

Quotidiana/Interpretação da Doxa

- Análise sócio-histórica (Situações espaço-

temporais; campos de interação; instituições

Conhecer Para Cuidar Melhor

Contexto da política

sociais; estrutura social; meios técnicos de

transmissão)

Análise formal ou discursiva (análise semiótica; análise de conversação; análise sintática; análise narrativa; análise

Cuidar para Confrontar

Relações institucionais operativa. De forma esquemática, tem-se a figura a seguir, seguida de especificação de cada uma das dimensões (Figura 1).

\section{Contexto da política}

Diz respeito às principais condições estruturais nas quais o "campo-sujeito-objeto" está inserido. Interessa a conjuntura em que são geradas as ações da política pública, os atores estratégicos, as definições ou indefinições políticas, as condições sociais e econômicas que interferem na conformação da ajuda-poder. Essa dimensão corresponderia ao contexto geral e análise sócio-histórica da hermenêutica de profundidade, portanto com a intenção de abranger, além da conjuntura na qual são produzidas as vivências do senso comum, os aspectos mais estruturados que constituem o "campo-objeto" (situações espaço-temporais; campos de Interação; instituições sociais; estrutura social; meios técnicos de transmissão). O propósito maior é compreender o contexto sócio-histórico onde se forja o cuidado à saúde, nas múltiplas possibilidades de domínio e subversão em que ele se funda.

\section{Relações institucionais}

Inseridas dialogicamente no contexto sóciohistórico, a dimensão "relações institucionais" diz respeito aos atores que fazem parte da política (incluindo a participação e organização da sociedade civil), suas articulações, interesses, correlações de força e significados. Elas seriam analisadas tendo por foco as disputas de poder e conquistas realizadas. Interessa captar a estruturação que as formas simbólicas podem adquirir no contexto das relações sociais, expressas por símbolos, falas, textos e discursos a serviço do poder. Tem relação com a análise formal da HP e procura interpretar a estrutura e o sentido do discurso gerado no interior das relações sociais. Investiaga-se, principalmente, como as tensões entre ajuda e poder se inserem no cotidiano das decisões governamentais da política, delineando-se poderes e contra-poderes.

\section{Dinâmica operativa}

$\mathrm{Na}$ tentativa de realizar sínteses provisórias, a "dinâmica operativa" se refere às ações produzidas, aos produtos e seus impactos sobre o contexto sóciohistórico. Diz respeito ao desempenho dos programas no contexto analisado, estando intimamente correlacionada às dimensões anteriores (relações institucionais e contexto da política). Seria a "interpretação ou reinterpretação" da HP, mantendo-se aberta às reconstruções e reposicionamentos analíticos. De modo geral, observam-se as sínteses possíveis entre ajuda e poder, bem como as possibilidades de tutela e subversão aí presentes. $\mathrm{Ou}$, de outra forma, estuda as possibilidades emancipatórias presentes nos cenários oportunizados pela gestão da ajuda-poder, captando dinamicidades e estruturas próprias de realidades complexas.

$\mathrm{Na}$ tentativa de montar um instrumental que auxilie a avaliação de políticas, programas e serviços 
Tabela 1

Avaliação em saúde a partir do triedro emancipatório do cuidar - referências teórico-metodológicas para a identificação de cenários de autonomia e poder.

Triedro Dimensão $\begin{gathered}\text { Categorias/ } \\ \text { Questões }\end{gathered}$ Parâmetros qualitativos

Conhecer para A - Contexto Gestão e

cuidar melhor da política conjuntura do poder
A1 - Conjuntura em que a política de saúde se insere é entendida como correlações de forças pelos atores, resultado de processo histórico dinâmico e complexo.

A2 - Política de saúde/programa/serviço segue princípios, diretrizes e arcabouço jurídico -institucional consensuados na esfera pública e assentes na efetiva ampliação da participação da sociedade civil (cidadania).

A3 - A gestã grama/serviço preocupa-se constantemente em conhecer/compreender a conjuntura da política para melhor decidir/gerir cenários de cuidado à saúde.

A4 - Inserção da política, programa/serviço de saúde na organização ocorre de forma priorizada, traduzida no orçamento e na autonomia gerencial.

Qual a conjuntura em que são geradas as

A5 - Ações intersetoriais permeariam o cotidiano institucional, constituindo-se em espaços dialogados de saberes.

relações de ajuda- A6 - Gestão das ações se organizariam a partir das forças sociais, com avaliações, poder no âmbito do programa ou serviço? reprogramações sistemáticas e controle democrático efetivamente delineado.

A7 - Política de formação profissional e educação permanente seria definida, gerida e forjada a partir da realidade dos sujeitos (foco na autonomia e construção de projetos próprios).

B1 - Panorama das forças sociais que influenciariam estrategicamente a política social (parlamentares, governo, empresas, setores organizados do mercado e da sociedade civil, sindicatos, universidades, conselhos de saúde, fóruns de negociação, outros) é constantemente analisado no processo decisório dos técnicos e gestores do programa/seviço.

B2 - Tensões e nós-críticos que influenciariam as relações entre atores do progra$\mathrm{ma} / \mathrm{serviço} \mathrm{e} \mathrm{demais} \mathrm{participantes} \mathrm{da} \mathrm{política} \mathrm{social} \mathrm{(inferências} \mathrm{internas} \mathrm{e} \mathrm{externas}$ que geram conflitos e/ou emperram ações e desempenhos) - mapeamento das forças e correlações.

e disputam espaços na conformação das B3 - Efetivo Controle Democrático (de baixo para cima): proposições demandadas pela relações de ajudapoder?

sociedade civil que foram atendidas pela gestão do programa/serviço:

- conselhos de políticas públicas e setores organizados da sociedade civil têm influência estratégica na priorização de ações, mobilizando atores e recursos para consecução das ações.

B4 - Democratização de poderes na esfera pública:- decisões e/ou deliberações de conselhos e/ou fóruns de negociação da política de saúde seriam condições estratégicas efetivas para a gestão e implementação do programa.

Cuidar para emancipar
C - Dinâmica Poder-autonomia operativa de sujeitos

O Programa ou serviço tem oportunizado cenários propícios à autonomia de sujeitos? Tal autonomia se traduz em ampliação do acesso e resolubilidades dos serviços/ações de saúde, aquilatados com equidade e participação social?
C1 - Gerência/condução do programa teria nível de decisão institucional elevado no que se refere a orçamento, projetos e ações.

C2 - Consonância dos princípios, diretrizes e/ou missões se traduzem em metas e objetivos alcançados e constantemente avaliáveis/reprogramáveis.

C4 - Ampliação de acessos e resolubilidades da atenção verificáveis em indicadores selecionados, mediados pelo controle das ações da sociedade civil sobre o Estado

C3 - As ações seriam definidas e reprogramadas constantemente, operando a partir da demanda, de informações sistematizadas e em diálogo com as forças sociais.

C4 - Desenvolvimento de ações intersetoriais para intervenção nos problemas prioritários, com demarcação de atribuições e avaliações sistemáticas.

C5 - Proposições seriam desenvolvidas pela gestão do programa/serviços a partir dos conselhos de política pública ou setores organizados da sociedade.

C6 - Gestão da ajuda-poder centrar-se-ia na educação permanente e oportunizaria cenários onde a autonomia dos sujeitos se manifesta (construção de projetos próprios, pressão e disputa por espaços, diálogos e trocas de saberes, luta por cidadania, outros). 
de saúde, especialmente no que se refere à identificação de cenários de autonomia e poder, propõe-se o quadro a seguir, que pode subsidiar a construção de indicadores/variáveis necessários e adaptáveis aos objetivos de cada estudo.

\section{Conclusões}

A politicidade do cuidado como referência indutora de mudança aposta numa ajuda que prioriza a autonomia e a elaboração própria dos sujeitos. Tal intento, no âmbito das políticas e sistemas de saúde, sugere passar de técnico à agente público de mudança, de administrador de decisões à formulador e indutor das mesmas, de "paciente" a cidadão, de 'doente' à pessoa humana, capaz tanto de sapiência criativa, quanto demolição destruidora, mas na perfeita imperfeição que conforma o ser humano

\section{Referências}

1. Pires MRGM. Politicidade do cuidado como referência emancipatória para a gestão de políticas de saúde: conhecer para cuidar melhor, cuidar para confrontar, cuidar para emancipar [tese de doutorado]. Brasília (DF): Departamento de Serviço Social da Universidade Federal de Brasília; 2004.

2. Demo P. Politicidade: razão humana. Campinas; Papirus; 2002.

3. Prigogine I, Stengers I. A nova aliança - a metamorfose da ciência. Brasília (DF): UNB; 1997.

4. Maturana HR, Varela FJG. De máquinas e seres vivosautopoiese: a organização do vivo. 3. ed. Porto Alegre; Artes Médicas; 1997.

5. Pires MRGM. Concepções de cuidado emancipatório: limites-possibilidades para as práticas profissionais no contexto das políticas de saúde do Brasil. Rev Sersoc 2002; 10: 147-68.

6. Boff L. Saber cuidar: ética do humano. 3. ed. São Paulo; Vozes; 1999.

7. Heidegger M. Ser e tempo. Parte 1. 12. ed . Petrópolis; Vozes; 2002.

8. Ayres JRCM. O Cuidado, os modos de ser (do) humano e as práticas de saúde. Rev Saúde Soc; 2004; 13: 16-29.

9. Bauman Z. Modernidade líquida. Rio de Janeiro: Jorge Zahar; 2001.

10. Gronemeyer M. Ajuda. In: Sachs W. Dicionário do desenvolvimento: guia para o conhecimento como poder. Petrópolis: Vozes; 2000.

11. Mauss M. Ensaio sobre a dádiva. Lisboa: Edições 70; 1950.

12. Foucault M. Microfísica do poder. 10. ed. Rio de Janeiro: Graal; 1979.

13. Foucault M. História da sexualidade. I: A vontade de saber. 7. ed. Rio de Janeiro: Graal; 1985.

14. Hardt M, Negri A. Império. 4. ed. Rio de Janeiro: Record; 2002. enquanto vida. No que se refere a avaliação de políticas, serviços e programas de saúde, tal concepção se expressa pela articulação do triedro do cuidar aqui discutido com reflexões mais ambivalentes e democráticas da avaliação, que contemplem a participação dos atores nos cenários avaliados. A título de breve síntese da articulação entre politicidade do cuidado e a avaliação em saúde, pode-se falar em "avaliar para conhecer e cuidar melhor, avaliar para indicar cenários de autonomia e poder, avaliar para cuidar da autonomia de sujeitos". Essa premissa se viabiliza nas dimensões, categorias e parâmetros acima adotados, constituindo-se numa referência teórico-metodológica importante para indicar cenários propícios ao fomento do protagonismo histórico, tendo por imagem-objetivo a implementação dos princípios e diretrizes do Sistema Único de Saúde.
15. Morin E. Método 3: O conhecimento do conhecimento. Porto Alegre: Sulina; 1999.

16. Morin E. Método 5: A humanidade da humanidade. Porto Alegre: Sulina; 2002.

17. Minayo MCS, Assis SG, Souza ER. Avaliação por triangulação de métodos - abordagem para programas sociais. Rio de Janeiro: Fiocruz; 2005.

18. Merhy EE. SUS e um de seus dilemas: mudar a gestão e a lógica do processo de trabalho em saúde (um ensaio sobre a macropolítica do trabalho vivo). In: Fleury S, organizador. Saúde e democracia - a luta do CEBES. São Paulo: Lemos; 1997.

19. Santos BS. Pela mão de Alice - o social e o político na pósmodernidade. 2. ed. São Paulo: Cortez; 1997

20. Demo P.Complexidade e aprendizagem - a dinâmica nãolinear do conhecimento. São Paulo: Atlas; 2002.

21. Gilmore R. Alice no país no quantum.Rio de Janeiro: Jorge Zahar; 1998.

22. Donabidian A. Na introduction to quality assurance in health care. Oxford: Oxford University Press; 2003.

23. Saul AM. Avaliação participante - uma abordagem criticotransformadora. In: Rico EM, organizador. Avaliação de políticas sociais - uma questão em debate. São Paulo: Cortez; 2001.

24. Vasconcelos EM. O poder que brota da dor e da opressão empowerment, sua história, teorias e estratégias. São Paulo: Paulus; 2003.

25. Thompson JB. Ideologia e cultura moderna - teoria social crítica na era dos meios de comunicação de massa. Petrópolis: Vozes; 1995.

26. Demo P. Pesquisa e informação qualitativa: aportes metodológicos. Campinas: Papirus; 2001.

Recebido em 11 de julho de 2005

Versão final apresentada em 18 de novembro de 2005

Aprovado em 21 de novembro de 2005 